УДК 796

DOI $10.21661 / \mathrm{r}-472797$

\title{
Н.А. Воронов
}

\section{ФИЗИЧЕСКАЯ КУЛЬТУРА КАК КОМПОНЕНТ ЗДОРОВОГО ОБРАЗА ЖИЗНИ ЧЕЛОВЕКА В ОБЩЕСТВЕ}

Аннотация: данная статья рассматривает вопросы необходимости занятий спортом для поддержания организма в здоровом состоянии, о необходимости занятий физической культурой для поддержания здорового образа жизни. Рассматриваются различные методы и способы развития личности. В наше время физическая культура является неотъемлемой частью жизни любого гражданина. Несомненно, улучшение здоровья напрямую зависит от потраченных на физические упражнения часов. Здоровье - это первая и самая важная потребность человека, которая определяет его способность к труду и обеспечивает гармоническое развитие личности.

Ключевые слова: здоровый образ жизни, физическая культура, спорт, правильное питание, эмоциональный настрой, общество.

\section{N.A. Voronov}

\section{PHYSICAL CULTURE AS THE COMPONENT OF HEALTHY LIFESTYLE OF THE PERSON IN SOCIETY}

Abstract: this article considers questions of need of sports activities for maintenance of an organism in a healthy state, about need of physical culture occupation for maintenance of a healthy lifestyle. Various methods and ways of development of the personality are considered. Nowadays the physical culture is an integral part of life of any citizen. Undoubtedly, improvement of health directly depends on the hours spent for physical exercises. Health is the first and most important need of the person which defines his ability to work and provides harmonious development of the personality.

Keywords: healthy lifestyle, physical culture, sport, healthy nutrition, emotional spirit, society. 
В настоящее время люди все больше и больше задумываются о важности здорового образа жизни. Здоровье в первую очередь для многих людей это состояние полного комфорта как физического, так и психологического. То есть такое состояние, при котором человек себя чувствует максимально удовлетворенным, у него ничего не болит, всё максимально благополучно. Человек обладающий хорошим здоровьем преобразует мир вокруг себя, он готов учиться, саморазвиваться и такой человек абсолютно счастливый.

Здоровый образ жизни или сокращённо ЗОЖ это такой образ поведения, тип жизнедеятельности, который основывается на закаливании своего духа и накопление своих внутренних сил, это человек который обладает невероятным стимулом саморазвиваться быть здоровым, счастливым, ограждая себя от различных неблагоприятных негативных факторов извне [2]. Здоровье это не только не наличие каких-то патологий, но общее приятное самочувствие. Даже при наличии какой-либо болезни человек может себя чувствовать здорово, а другой человек, у которого, казалось бы, не найдено никаких патологий, чувствует себя нездоровым. Вообще, стоит выделить три вида здоровья: физическое здоровье, нравственное здоровье и психологическое здоровье.

Физическое здоровье - это такое состояние нашего организма, когда он гармонично функционирует со всеми органами и с каждой молекулой нашего тела. Если все наши внутренние органы работают слаженно, то и весь организм чувствует себя хорошо и функционирует правильно. Психологическое здоровье зависит в первую очередь от состояния нашего головного мозга, то есть он характеризуется тем уровнем нашего мировоззрения, тем вниманием и памятью который мы обладаем, а также степенью нашей эмоциональной стабильности.

Нравственное здоровье - в первую очередь указывает на особенность моральных принципов, которые являются основным стержнем, на котором строится все остальные постулаты и все остальные правила жизни для человека. Особенностями нравственного здоровья является личное отношение к человеку труду, к семье, к своему здоровью и т. д. 
Целостность и гармония человека связана в первую очередь с тем, как взаимодействует его физические и психологические силы. Если все эти факторы находятся в полной гармонии, то они повышают иммунитет человека, организм человека становится невосприимчивым к конечным патологиям и внешним возбудителям, становится более крепким [3].

Можно выявить резервы наших органов: желчного пузыря, печени, почек, сердца, легких и так далее. Уровень, при котором определяется, то, что здоровье это всё-таки количество резервов организма, который способен противостоять внешним возбудителям. Чем больше резервов, тем более сильный организм. Как известно труд украшает человека. И наиболее долгоживущие люди в основном располагаются в горах Кавказа. И это отнюдь не связано с их местоположением. А связано с их постоянным желанием работать не в грязном душном офисе, а работать на природе, то есть трудиться. Такие люди помимо постоянного труда, правильно питаются экологически чистыми продуктами, вовремя отдыхают, даже отдых проходит, не лежа на диване, а в горах или на берегу моря. Такие люди практически полностью отказываются от вредных привычек, таких как алкоголь или курение. Они постоянно двигаются, их жизнь не стоит на месте, они вечно соблюдают гигиену, практикуют контрастный душ, раздельное питание и так далее. Так стоит отметить, что режим труда и отдыха - это наиболее важный компонент здорового образа жизни [1]. При правильном и постоянно соблюдении режима наш организм вырабатывает биологический ритм сна и бодрствования.

Следующим элементом здорового образа жизни является полный отказ от различных вредных привычек. Они негативно влияют на общее самочувствие, на состояние многих наших органов, в первую очередь страдают печень, почки и легкие.

Следующим пунктом здорового образа жизни является закаливание и контрастный душ. В России издревна занимались закаливанием [4]. Как известно закаливание оказывает огромное влияние на укрепление иммунитета человека. Всё-таки наиболее постепенное чередование тёплых или горячих и холодных 
температур необходимо для нашего организма. Такое закаливание улучшает эластичность наших сосудов, кожи, помогает в случае проникновения вирусных инфекций или бактерий и помогает организму лучше сопротивляться. Также закаливание можно назвать конечно же мощным оздоровительный эффектом позволяющим избежать многих болезней, позволяющим улучшить и продлить нашу жизнь на многие годы, а также улучшить качество нашей кожи и наше состояние.

\section{Список литературы}

1. Воронов Н.А. Феномен социализации студента в образовательном процессе физического развития / Н.А. Воронов, И.П. Гладких, А.В. Люсин // Образование и педагогические науки в XXI веке: Сборник статей победителей Международной научно-практической конференции / Под общей редакцией Г.Ю. Гуляева. - 2017. - С. 162-165.

2. Виленский М.Я. Физическая культура и здоровый образ жизни студента: Учебное пособие / М.Я. Виленский, А.Г. Горшков. - М.: КноРус, 2013. - 240 с.

3. Виноградов П.А. Физическая культура и спорт трудящихся / П.А. Виноградов, Ю.В. Окуньков. - М.: Советский спорт, 2015. - 172 с.

4. Петленко В.П. Основы валеологии / В.П. Петленко. Кн. 3. - 1999. - 433 с.

\section{References}

1. Voronov, N. A., Gladkikh, I. P., \& Liusin, A. V. (2017). Fenomen sotsializatsii studenta $\mathrm{v}$ obrazovatel'nom protsesse fizicheskogo razvitiia. Obrazovanie i pedagogicheskie nauki v XXI veke.

2. Vilenskii, M.Ia., \& Gorshkov, A.G. (2013). Fizicheskaia kul'tura i zdorovyi obraz zhizni studenta: Uchebnoe posobie. M.: KnoRus.

3. Vinogradov, P. A., \& Okun'kov, Iu. V. (2015). Fizicheskaia kul'tura i sport trudiashchikhsia. M.: Sovetskii sport.

4. Petlenko, V.P. Osnovy valeologii., 433.

Воронов Николай Андреевич - канд. биол. наук, старший преподаватель ФГКВОУ ВО «Ярославское высшее военное училище противовоздушной 
обороны» Минобороны России; доцент ФГБОУ ВО «Ярославский государственный университет им. П.Г. Демидова», Россия, Ярославль.

Voronov Nikolai Andreevich - candidate of biological sciences, senior lecturer at the Yaroslavl Aerospace Military Academy of the Ministry of Defence of the Russain Federation; associate professor at the Yaroslavl state university named after P.G. Demidov, Russia, Yaroslavl. 